\title{
Editorial
}

\section{Nonlinear Time Series: Computations and Applications}

\author{
Ming Li, ${ }^{1}$ Massimo Scalia, ${ }^{2}$ and Cristian Toma ${ }^{3}$ \\ ${ }^{1}$ School of Information Science E Technology, East China Normal University, No. 500, Dong-Chuan Road, \\ Shanghai 2002411, China \\ 2 Department of Mathematics "G. Castelnuovo", University of Rome 00185 Rome, Italy \\ ${ }^{3}$ Faculty of Applied Sciences, Politehnica University, Street Hagi-Ghita No. 81, 060042 Bucharest, Romania \\ Correspondence should be addressed to Ming Li, ming_lihk@yahoo.com
}

Received 24 August 2010; Accepted 24 August 2010

Copyright (C) 2010 Ming Li et al. This is an open access article distributed under the Creative Commons Attribution License, which permits unrestricted use, distribution, and reproduction in any medium, provided the original work is properly cited.

There are thirty six papers collected in this special issue, but they do not cover the rich contents of nonlinear time series. Therefore, we cite a few references in this forward to facilitate for readers to obtain a fine profile of this attractive area. They are Luczka [1], Abel and Schwarz [2], Schreiber [3], West and Deering [4], Beran [5], Mandelbrot [6], Adler et al. [7], Touchette [8], Abry et al. [9], Werner [10], Cattani and Rushchitsky [11], Cattani [12, 13], Kantz and Schreiber [14], Fan and Yao [15], Bec and Khanin [16], Bouchaud and Georges [17], Baillie and King [18], Li and Borgnat [19], Parker and Chua [20], T. Machado et al. [21], Bakhoum and Toma [22], and Li and Zhao [23].

In this special issue, the first paper by $\mathrm{Li}$ [24] gives a tutorial of fractal time series from the point of view of systems of fractional order. The second by Liu [25] provides a review of chaotic time series. The third by Cattani [26] reveals the fractal shapes and the symmetries of DNA from a view of fractal time series. The fourth one by Mattioli et al. [27] studies largeamplitude pulses with the FitzHugh-Nagumo model to exhibit the sensitivity to local jumps and some unexpected inertia of neurons as response to the high-amplitude spike. The fifth paper by Bakhoum and Toma [28] investigates the dynamics of macroscopic and quantum transitions. The paper by Toma [29] presents a method to synthesize pulse series based on nonlinear differential equations. Abuzeid et al. [30] contributes a paper for constructing a continuous hereditary creep model for the thermoviscoelastic contact of a rough punch and a smooth surface of a rigid half-space. The paper by Zhao et al. [31] discusses the detrended fluctuation analysis method to detect the long-range correlation and scaling properties of daily precipitation series of Beijing from 1973 to 2004 before and after adding diverse trends to the original series. 
Seven papers in the applications of nonlinear time series to computer science are collected in this issue. The paper by He et al. [32] shows an improved scheme of block cipher based on dynamic sequences generated by multiple chaotic systems. Peng et al. contribute their paper [33] in the field of chaotic communications. The paper by Zheng et al. [34] gives a method to build representative-based data aggregation tree in wireless sensor networks for the security purpose and opens a problem of how to evaluate the life time of the proposed method from a view of time series. Two papers, respectively, by $\mathrm{Li}$ and $\mathrm{Li}$ [35] and Xia et al. [36] are in the field of intrusion detection. The paper by Chen et al. [37] proposes an approach for estimating the space usage of skyband operator over sliding windows of data streams. The paper by Chen et al. [38] presents an improved algorithm of adaptive random early detection.

Prediction is an interesting topic in time series. The paper by M. Li and J.-Y. Li [39] gives a proof of the predictability of long-range-dependent series. Dong [40] reviews the concepts, models, and algorithms with respect to nonlinear time-series data mining in engineering asset health and reliability prediction. She and Yang's paper (see [41]) provides a method in adaptive local linear prediction and its application to hydrological time series. The paper by Shang et al. [42] discusses the method of max-margin classification for prediction. Leon and Zaharia's paper [43] addresses stacked heterogeneous neural networks for time series forecasting.

We collected 7 papers in the area of applications of nonlinear time series to signal and image processing. The paper by Huang and Qiu [44] proposes a blind deconvolution procedure for estimating a regression function with possible jumps preserved by removing both noise and blur when recovering the signals. The paper by Friston et al. [45] generalizes the concept and theory of filtering. Sterian and Toma's paper is presented in [46], which discusses the method of signal processing and sampling for obtaining time series corresponding to higher-order derivatives, which is desired in modeling and controlling dynamic phenomena. Liao et al. in their paper [47] address adaptive image denoising using nonlinear time series analysis. The paper by Li et al. [48] shows an application of nonlinear spectral subtraction method to millimeter wave conducted speech enhancement. The paper by Shan and Li [49] discusses the analysis of nonlinearity of signals from a view of timefrequency distributions. The paper by Sung et al. [50] is an application of time series to the design of very large-scale integrated circuits.

The paper by Chen et al. [51] deals with the outliers and patches in bilinear time series. The paper by $\mathrm{Hu}$ [52] studies the quasimaximum likelihood method to estimate unknown parameters in autoregressive processes. $\mathrm{Li}$ and $\mathrm{Pu}$ 's paper [53] gives a scheme of the hypothesis designs of the three-hypothesis test problems. The paper by Nefeslioglu et al. [54] is an application article in geoscience. The paper by Sevimlican [55] is in the field of systems of fractional order. The paper by Farooq et al. [56] investigates a prior knowledge-based Green's kernel for support vector regression. Humi's paper [57] assesses the local turbulence strength from the point of view of time series by establishing the relationship between local turbulence strength and the Lyaponuv exponent in a flow. The paper by Messina et al. [58] may be taken as an initiative work in the aspect of spatial analysis of the nonstationary timefrequency dynamics of oscillatory processes in power systems. The paper by Carlini et al. [59] is in the field of precision agriculture, exploring a greenhouse model towards maximizing the cooling system consumption of energy. 


\title{
Acknowledgments
}

The authors are grateful to the authors of the special issue for their contributions. They thank the reviewers for their valuable comments on the submissions. They highly appreciate the support from Professor José Manoel Balthazar (the editor-in-chief) and the editorial members of Mathematical Problems in Engineering, as well as the editorial staff of Hindawi Publishing Corporation. M. Li acknowledges the support from the National Natural Science Foundation of China (NSFC) under the Project Grants no. 60573125, 60873264, 61070214, and the 973 plan under the Project no. 2011CB302800/2011CB302802.

\author{
Ming Li \\ Massimo Scalia \\ Cristian Toma
}

\section{References}

[1] J. Luczka, "Non-Markovian stochastic processes: colored noise," Chaos, vol. 15, no. 2, Article ID 026107, 13 pages, 2005.

[2] A. Abel and W. Schwarz, "Chaos communications-principles, schemes, and system analysis," Proceedings of the IEEE, vol. 90, no. 5, pp. 691-710, 2002.

[3] T. Schreiber, "Interdisciplinary application of nonlinear time series methods," Physics Report, vol. 308, no. 1, pp. 1-64, 1999.

[4] B. J. West and W. Deering, "Fractal physiology for physicists: Lévy statistics," Physics Report, vol. 246, no. 1-2, pp. 1-100, 1994.

[5] J. Beran, Statistics for Long-Memory Processes, Chapman \& Hall, Boca Raton, Fla, USA, 1994.

[6] B. B. Mandelbrot, Gaussian Self-Affinity and Fractals, Springer, New York, NY, USA, 2001.

[7] R. J. Adler, R. E. Feldman, and M. S. Taqqu, Eds., A Practical Guide to Heavy Tails: Statistical Techniques And Applications, Birkhäauser, Boston, Mass, USA, 1998.

[8] H. Touchette, "The large deviation approach to statistical mechanics," Physics Reports, vol. 478, no. 1-3, pp. 1-69, 2009.

[9] P. Abry, P. Borgnat, F. Ricciato, A. Scherrer, and D. Veitch, "Revisiting an old friend: on the observability of the relation between long range dependence and heavy tail," Telecommunication Systems, vol. 43, no. 3-4, pp. 147-165, 2009.

[10] G. Werner, "Fractals in the nervous system: conceptual implications for theoretical neuroscience," Frontiers in Fractal Physiology, vol. 1, no. 15, 28 pages, 2010.

[11] C. Cattani and J. J. Rushchitsky, Wavelet and Wave Analysis as Applied to Materials with Micro or Nanostructure, World Scientific, Singapore, 2007.

[12] C. Cattani, "Harmonic wavelet approximation of random, fractal and high frequency signals," Telecommunication Systems, vol. 43, no. 3-4, pp. 207-217, 2010.

[13] C. Cattani, "Shannon wavelets theory," Mathematical Problems in Engineering, vol. 2008, Article ID 164808, 24 pages, 2008.

[14] H. Kantz and T. Schreiber, Nonlinear Time Series Analysis, Cambridge University Press, New York, NY, USA, 1999.

[15] J. Fan and Q. Yao, Nonlinear Time Series: Nonparametric and Parametric Methods, Springer, New York, NY, USA, 2005.

[16] J. Bec and K. Khanin, "Burgers turbulence," Physics Reports, vol. 447, no. 1-2, pp. 1-66, 2007.

[17] J.-P. Bouchaud and A. Georges, "Anomalous diffusion in disordered media: statistical mechanisms, models and physical applications," Physics Report, vol. 195, no. 4-5, pp. 127-293, 1990.

[18] R. T. Baillie and M. L. King, "Eidtors' introduction: fractional differencing and long memory processes," Journal of Econometrics, vol. 73, no. 1-2, pp. 1-3, 1996.

[19] M. Li and P. Borgnat, "Forward to the special issue on traffic modeling, its computations and applications," Telecommunication Systems, vol. 43, no. 3-4, pp. 145-146, 2010.

[20] T. S. Parker and L. O. Chua, "Chaos: a tutorial for engineers," vol. 75, no. 8, pp. 982-1008.

[21] J. A. Tenreiro Machado, M. F. Silva, R. S. Barbosa et al., "Some applications of fractional calculus in engineering," Mathematical Problems in Engineering, vol. 2010, Article ID 639801, 34 pages, 2010. 
[22] E. G. Bakhoum and C. Toma, "Relativistic short range phenomena and space-time aspects of pulse measurements," Mathematical Problems in Engineering, vol. 2008, Article ID 410156, 20 pages, 2008.

[23] M. Li and W. Zhao, "Representation of a stochastic traffic bound," IEEE Transactions on Parallel and Distributed Systems, vol. 21, no. 9, pp. 1368-1372, 2010.

[24] M. Li, "Fractal time series-a tutorial review," Mathematical Problems in Engineering, vol. 2010, Article ID 157264, 26 pages, 2010.

[25] Z. Liu, "Chaotic time series analysis," Mathematical Problems in Engineering, vol. 2010, Article ID 720190, 31 pages, 2010.

[26] C. Cattani, "Fractals and hidden symmetries in DNA," Mathematical Problems in Engineering, vol. 2010, Article ID 507056, 31 pages, 2010.

[27] G. Mattioli, M. Scalia, and C. Cattani, "Analysis of large-amplitude pulses in short time intervals: application to neuron interactions," Mathematical Problems in Engineering, vol. 2010, Article ID 895785, 15 pages, 2010.

[28] E. G. Bakhoum and C. Toma, "Dynamical aspects of macroscopic and quantum transitions due to coherence function and time series events," Mathematical Problems in Engineering, vol. 2010, Article ID 428903, 13 pages, 2010.

[29] G. Toma, "Specific differential equations for generating pulse sequences," Mathematical Problems in Engineering, vol. 2010, Article ID 324818, 11 pages, 2010.

[30] O. M. Abuzeid, A. N. Al-Rabadi, and H. S. Alkhaldi, "Fractal geometry-based hypergeometric time series solution to the hereditary thermal creep model for the contact of rough surfaces using the Kelvin-Voigt medium," Mathematical Problems in Engineering, vol. 2010, Article ID 652306, 22 pages, 2010.

[31] X. Zhao, J. Yue, and P. Shang, "Effect of trends on detrended fluctuation analysis of precipitation series," Mathematical Problems in Engineering, vol. 2010, Article ID 749894, 15 pages, 2010.

[32] J. He, H. Qian, Y. Zhou, and Z. Li, "Cryptanalysis and improvement of a block cipher based on multiple chaotic systems," Mathematical Problems in Engineering, vol. 2010, Article ID 590590, 14 pages, 2010.

[33] H. Peng, Y. Shao, L. Li, and Y. Yang, "Cryptanalysis of a chaotic communication scheme using parameter observer," Mathematical Problems in Engineering, vol. 2010, Article ID 361860, 18 pages, 2010.

[34] Y. Zheng, K. Chen, and W. Qiu, "Building representative-based data aggregation tree in wireless sensor networks," Mathematical Problems in Engineering, vol. 2010, Article ID 732892, 11 pages, 2010.

[35] M. Li and M. Li, "An adaptive approach for defending against DDoS attacks," Mathematical Problems in Engineering, vol. 2010, Article ID 570940, 15 pages, 2010.

[36] Z. Xia, S. Lu, and J. Tang, "Note on studying change point of LRD traffic based on Li's detection of ddos flood attacking," Mathematical Problems in Engineering, vol. 2010, Article ID 962435, 14 pages, 2010.

[37] L. Chen, J. Zhao, Q. Huang, and L. H. Yang, "Effective space usage estimation for sliding-window skybands," Mathematical Problems in Engineering, vol. 2010, Article ID 828035, 15 pages, 2010.

[38] J. Chen, C. Hu, and Z. Ji, "An improved ARED algorithm for congestion control of network transmission," Mathematical Problems in Engineering, vol. 2010, Article ID 329035, 14 pages, 2010.

[39] M. Li and J.-Y. Li, "On the predictability of long-range dependent series," Mathematical Problems in Engineering, vol. 2010, Article ID 397454, 9 pages, 2010.

[40] M. Dong, "A tutorial on nonlinear time-series data mining in engineering asset health and reliability prediction: concepts, models, and algorithms," Mathematical Problems in Engineering, vol. 2010, Article ID 175936, 22 pages, 2010.

[41] D. She and X. Yang, "A new adaptive local linear prediction method and its application in hydrological time series," Mathematical Problems in Engineering, vol. 2010, Article ID 205438, 15 pages, 2010.

[42] Z. Shang, S. Ma, B. Fang, and T. Zhang, "Incomplete time series prediction using max-margin classification of data with absent features," Mathematical Problems in Engineering, vol. 2010, Article ID 513810, 14 pages, 2010.

[43] F. Leon and M. H. Zaharia, "Stacked heterogeneous neural networks for time series forecasting," Mathematical Problems in Engineering, vol. 2010, Article ID 373648, 20 pages, 2010.

[44] X. Huang and P. Qiu, "Blind deconvolution for jump-preserving curve estimation," Mathematical Problems in Engineering, vol. 2010, Article ID 350849, 9 pages, 2010. 
[45] K. Friston, K. Stephan, B. Li, and J. Daunizeau, "Generalised filtering," Mathematical Problems in Engineering, vol. 2010, Article ID 621670, 34 pages, 2010.

[46] A. Sterian and A. Toma, "Signal processing and sampling method for obtaining time series corresponding to higher order derivatives," Mathematical Problems in Engineering, vol. 2010, Article ID 913147, 9 pages, 2010.

[47] Z. Liao, S. Hu, and W. Chen, "Determining neighborhoods of image pixels automatically for adaptive image denoising using nonlinear time series analysis," Mathematical Problems in Engineering, vol. 2010, Article ID 914564, 14 pages, 2010.

[48] S. Li, J. Q. Wang, and X. J. Jing, "The application of nonlinear spectral subtraction method on millimeter wave conducted speech enhancement," Mathematical Problems in Engineering, vol. 2010, Article ID 371782, 12 pages, 2010.

[49] P.-W. Shan and M. Li, "Nonlinear time-varying spectral analysis: HHT and MODWPT," Mathematical Problems in Engineering, vol. 2010, Article ID 618231, 14 pages, 2010.

[50] T.-Y. Sung, Y.-S. Shieh, and H.-C. Hsin, "An efficient VLSI linear array for DCT/IDCT using subband decomposition algorithm," Mathematical Problems in Engineering, vol. 2010, Article ID 185398, 21 pages, 2010.

[51] P. Chen, L. Li, J.-G. Lin, and Y. Liu, "Detection of outliers and patches in bilinear time series models," Mathematical Problems in Engineering, vol. 2010, Article ID 580583, 10 pages, 2010.

[52] H. Hu, "QML estimators in linear regression models with functional coefficient autoregressive processes," Mathematical Problems in Engineering, vol. 2010, Article ID 956907, 30 pages, 2010.

[53] Y. Li and X. Pu, "Hypothesis designs for three-hypothesis test problems," Mathematical Problems in Engineering, vol. 2010, Article ID 393095, 15 pages, 2010.

[54] H. A. Nefeslioglu, E. Sezer, C. Gokceoglu, A. S. Bozkir, and T. Y. Duman, "Assessment of landslide susceptibility by decision trees in the metropolitan area of Istanbul, Turkey," Mathematical Problems in Engineering, vol. 2010, Article ID 901095, 15 pages, 2010.

[55] A. Sevimlican, "An approximation to solution of space and time fractional telegraph equations by he's variational iteration method," Mathematical Problems in Engineering, vol. 2010, Article ID 290631, 10 pages, 2010.

[56] T. Farooq, A. Guergachi, and S. Krishnan, "Knowledge-based Green's Kernel for support vector regression," Mathematical Problems in Engineering, vol. 2010, Article ID 378652, 16 pages, 2010.

[57] M. Humi, "Assessing local turbulence strength from a time series," Mathematical Problems in Engineering, vol. 2010, Article ID 316841, 13 pages, 2010.

[58] A. R. Messina, P. Esquivel, and F. Lezama, "Time-dependent statistical analysis of wide-area timesynchronized data," Mathematical Problems in Engineering, vol. 2010, Article ID 751659, 17 pages, 2010.

[59] M. Carlini, S. Castellucci, M. Guerrieri, and T. Honorati, "Stability and control for energy production parametric dependence," Mathematical Problems in Engineering, vol. 2010, Article ID 842380, 21 pages, 2010. 


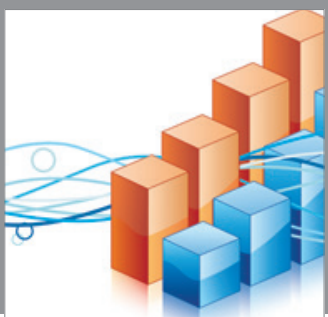

Advances in

Operations Research

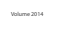

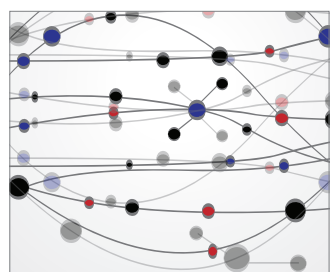

\section{The Scientific} World Journal
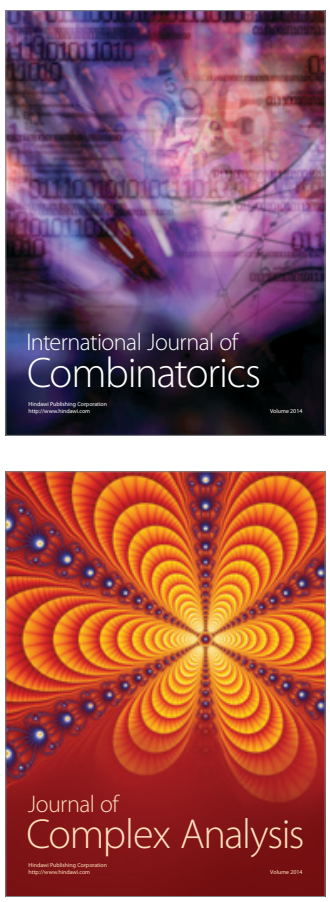

International Journal of

Mathematics and

Mathematical

Sciences
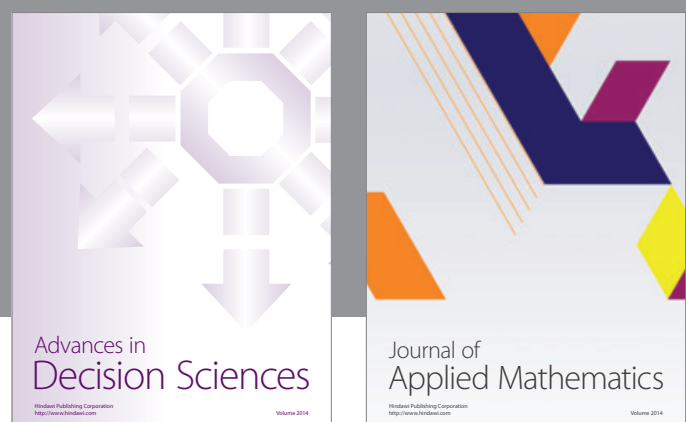

Journal of

Applied Mathematics
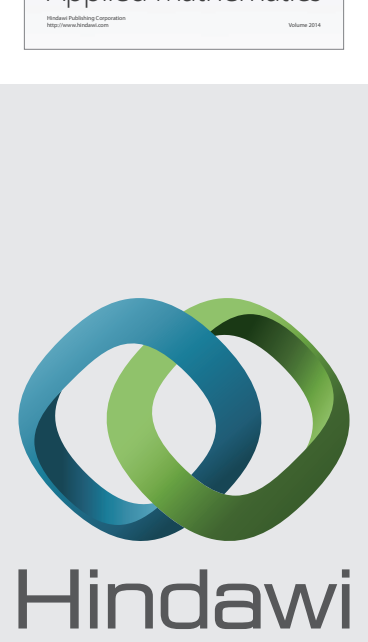

Submit your manuscripts at http://www.hindawi.com
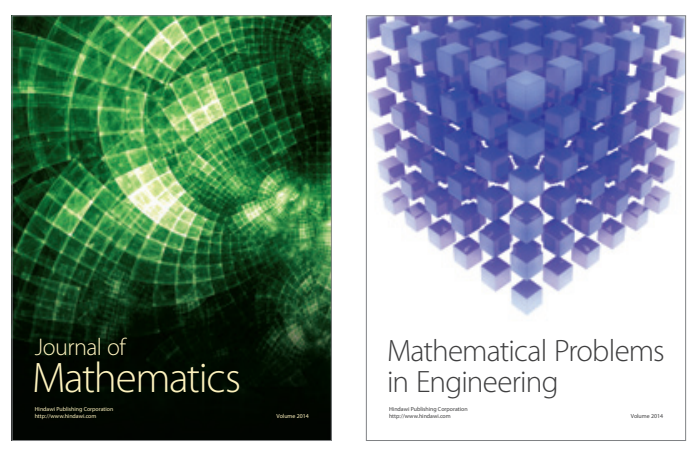

Mathematical Problems in Engineering
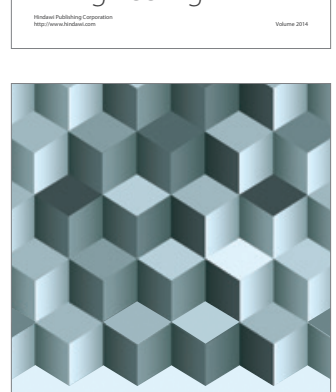

Journal of

Function Spaces
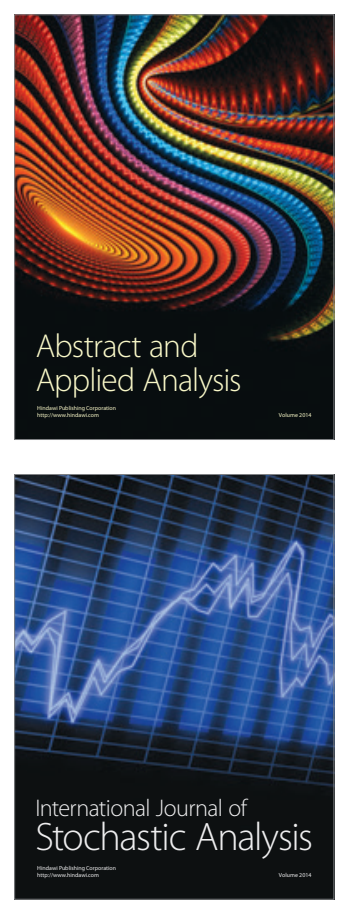

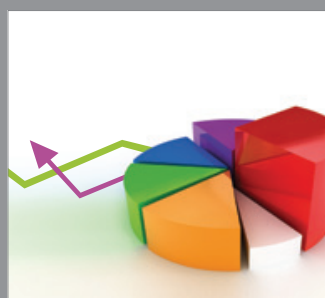

ournal of

Probability and Statistics

Promensencen
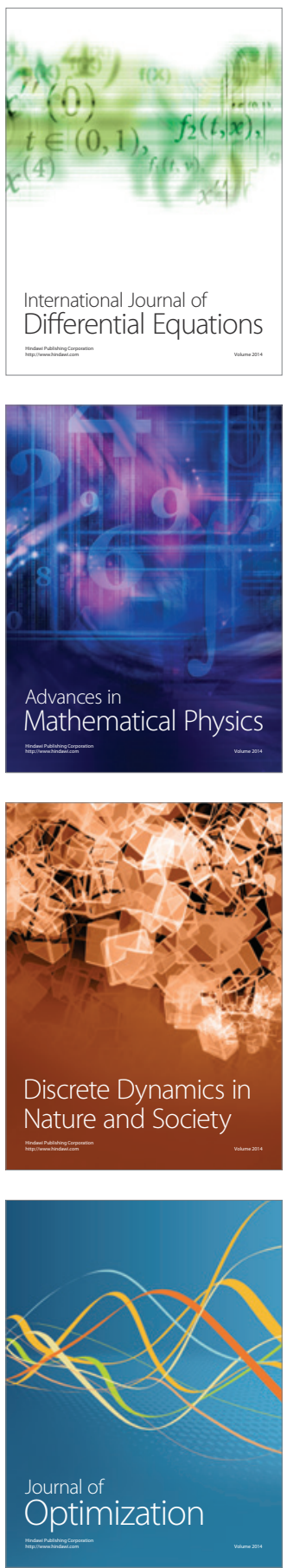